Dr. WILKs, F.R.S., will deliver the inaugural address of the Midland Medical Society for the session 1885-6, at Birmingham, on Wednesday evening, November 11th.

\section{THE NEW PHARMACOPCEIA.}

\section{BY J. G. BARFORD.}

Probably most general practitioners have, like myself, been looking forward to the issue of a new edition of the British Pharmacopoia. Placed, as many of us are, in country districts, with but little intercourse with our professional brethren, in the centres of thought and scientific advancement, we become largely dependent on the pages of THE LANCET and other medical journals to keep somewhat abreast with the rapidly developing professional knowledge. But as the information is scattered over many pages, and our time for reference very limited-in fact, the only time often at command being in the intervals of our visits while driving from house to house along a rough road in a not too easy vehicle, - the issue of an official guide like that of the Pharmacopoeia is looked forward to with more than usual interest. As the great bulk of professional labour has to be borne by the general practitioners of the country, and this, too, under the pressure of limited time and urgency, it would naturally be expected that the General Medical Council should consider their convenience as far as practicable in "a book containing a list of medicines and compounds, and the manner of preparing them." The practice of medicine has not yet assumed the form of an exact science, therefore aids to practice should be based on practical expediency where absolute scientific accuracy is not essential. But this view seems to be entirely ignored in the new Pharmacopoia, as it was to some extent in the last edition, compared with previous editions issued by the Royal College of Physicians. For example, the acidum sulphuricum dilutum is directed to be made by a complicated process involving a graduated flask, a thermometer, and " a sufficiency" of distilled water. It may fairly be asked what advantage this more complicated process has over the more simple one in the older Pharmacopœias, which consisted simply of measuring so much sulphuric acid and so much distilled water in the ordinary graduated dispensing measure and adding the acid gradually to the water? A prescription containing dilute sulphuric acid, if dispensed by six different druggists, would vary more in the actual amount of sulphuric acid contained in them than any two mixtures dispensed with scientific accuracy with acids made by the older and newer processes. What, then, is the practical advantage of the newer and more complicated process? Is it to necessitate a duly qualified pharmaceutical assistant as an appendage to the general practitioner, or to drive dispensing into the hands of the pharmaceutical chemist of assumed greater scientific aciuracy? Take, again, the instance of the decoctum aloes compositum and the complicated directions for its preparation in the present Pharmacopoia, compared with the simple process in the Pharmacopæia of 1809 , when it was first officinally introduced as a substitute for the then popular "beaume de vie." The older preparation would keep unchanged for any length of time, while the newer has to be "kept in vessels from which air is excluded as far as possible." Since the original introduction of this preparation it has undergone no less than three alterations in the quantity of aloes it contains, thus varying in strength from 333 grains to the ounce to 5.6 grains, while the original preparation contained 375 of aloes to the ounce. It may be asked, what advantage accrues from these changes? - what gain from making a simple process a complicated one? To the general practitioner it makes prescribing more difficult, to the compounder of medicines his art more complicated, to the patient there is no gain. The active ingredient, aloin, in all the preparations of aloes, has now come into very general use. The scientific accuracy aimed at elsewhere in the Pharmacopoia appears to be departed from in reference to this agent. The definite composition of $\mathrm{C}_{16} \mathrm{H}_{18} \mathrm{O}_{7}$ is given to it, but in the text it is represented as varying. "As obtained from the different varieties of aloes, the products differ slightly, but their medicinal properties are similar." It may be asked, is this variability a chemical or a physical one? On what does this similarity rather than identity of action depend? It is set forth in the preface of the Pharmacopoia that among the objects contemplated " has been that of promoting increased uniformity of strength and other properties, especially in certain of the more active medicines." Aloin is one of the more active medicines. Why cannot the same uniformity be attained in this as in the case of quinine? Aloin is rapidly altered in alkaline fluids, yet in the decoctum aloes compositum the alkaline potassium carbonate is still permitted to be an ingredient, notwithstanding that the actire principle is known to be changed in this alkaline solution, rendering the prescriber thereby uncertain as to the exact strength of the compound decoction he is prescribing. This admitted action of alkalies on aloin appears to call for the exclusion of the potassium carbonate, or other alkalies from all compounds of which aloes is an ingredient.

The preparations of arsenic are confusing both in regard to their nomenclature, and the doses in which they have to be prescribed-i.e., two to eight minims of one, ten to thirty minims of another, and five to ten minims of a third. Could not all these have been made of uniform arsenical strength? Scientific chemists differ as to the exact chemical constitution of a solution of arsenious acid with an alkali or with an acid. It is not necessary to determine for medicinal purposes whether the arsenious acid in the case of the alkaline solution plays the part of an acid and forms a compound with the alkaline base, nor whether in the acid solution the arsenious acid reverses it relation and becomes the base. Such questions are interesting chemical problems not yet solved, but the clinical fact is determined that these preparations of arsenic are less easily borne than the solution of definite sodium arseniate of the liquor sodii arseniatis of the Pharmacopoeia. Therefore the book need not have been encumbered with the two former preparations and their ambiguous unscientific nomenclature. But it is not only in the doses of the more active or poisonous remedies that there is a want of uniformity. The tinctures vary in dose from five to fifteen minims to two drachms, or, as in the case of tincture of rhubarb, to an ounce. Could not these have been prepared with some approach to uniformity of dose, the more potent tinctures being made weaker so as to correspond in dose with the milder preparations? Risk in prescribing would thereby be diminished without lessened efficacy. With reference to the dose of tinctures, that of the tincture of rhubarb is said to be eight fluid drachms as a purgative. The purgative effect of this dose would be overshadowed by the stimulating effect of the one ounce of proof spirit it would contain. Proof spirit consists of, by volume, about 57 per cent. of absolute alcohol, or what would be equal to a little more than three ounces of sherry of the Pharmacopoeia strength. This would be sufficient to intoxicate a person unaccustomed to stimulants. Here it may be mentioned that, though the quantity of absolute alcohol contained in rectified and proof spirit, as well as in sherry, is specified, the quantity that should be contained in brandy is not given. As brandy varies from 49 to 56 per cent. of alcohol, it is an important omission that the exact strength to be used is not mentioned. It is the chief ingredient in the mistura spiritus vini gallici, which is the all-important stimulant and nutrient in critical and extreme cases of illness. When it is advised, the practitioner has to make a hurried estimate of the quantity he should administer as a substitute for the weaker alcoholic stimulants which, in all probability, he has had administered to his patient. Wines of a little lesser or greater strength are not of so much importance; but when the case becomes so critical as to need brandy, or brandy compounds, the exact alcoholic strength is of paramount importance.

These defects in the Pharmacopoeia, viewed from the standpoint of a medical practitioner, are a few of the many that exist. It is more than thirty years ago since ideas on these subjects were first taught me by two out of the three editors of the Pharmacopoeia, and more than thirty years since I was a fellow-student under their teaching with the third editor, in the laboratory of the Pharmaceutical Society. Something of the scientific method they then imparted has slipped away in the hurry and bustle of general practice; but some of the requirements of the medical practitioner have been suggested in their place. A few of these, as here set forth, may elicit the views of others similarly engaged, and not be unworthy of the consideration of the compilers of the Pharmacopoia. Wokingham. 